\title{
Effective Antiemetic Therapy Is Important With Adjuvant Anthracycline-based Chemotherapy in Breast Cancer
}

\author{
LAURA TAKALA $^{1}$, MAARIT B ÄRLUND $^{2}$ and PIRKKO-LIISA KELLOKUMPU-LEHTINEN ${ }^{1,2}$ \\ ${ }^{1}$ Faculty of Medicine and Life Sciences, University of Tampere, Tampere, Finland; \\ ${ }^{2}$ Department of Oncology, Tampere University Hospital, Tampere, Finland
}

\begin{abstract}
Background: The aim of this study was to evaluate whether aprepitant is an effective antiemetic when combined with 5-hydroxytryptamine 3-(5-HT3) receptor antagonists and dexamethasone in patients with breast cancer receiving anthracycline-based chemotherapy. Patients and Methods: A retrospective study was carried out on 229 patients with breast cancer between 2004 and 2014. All the patients received three cycles of cyclophosphamide, epirubicin and 5-fluorouracil. 5-HT3 receptor antagonists and dexamethasone were used in 132 patients (cohort 1). 5-HT3 receptor antagonists, dexamethasone and aprepitant were used in 97 patients (cohort 2). The primary outcome was to compare the grades of emesis between cohorts 1 and 2. Results: The incidence of moderate and severe nausea was significantly lower in cohort 2 than in cohort $1(p<0.05)$ during all three cycles. Additionally, the complete response rate (i.e. no nausea) was higher in cohort $2(p<0.05)$. Conclusion: The combination of 5-HT3 receptor antagonists, dexamethasone and aprepitant was more effective as an antiemetic treatment than the standard dual combination of 5-HT3 receptor antagonists and dexamethasone for patients with breast cancer receiving anthracycline-based adjuvant chemotherapy.
\end{abstract}

Breast cancer is the most common type of cancer diagnosed in women worldwide $(1,2)$. Even though the incidence rates are increasing globally, breast cancer mortality is decreasing due to better diagnosis and treatments (1). In Finland in 2014, 5,008 new breast cancer cases were diagnosed, and 815 patients with breast cancer died (3). Breast cancer treatment usually consists of surgery with radiation therapy with/without systemic treatment with chemotherapy, hormone therapy and anti-human epidermal growth factor receptor 2 (HER2)-

Correspondence to: Laura Takala, MD, Faculty of Medicine and Life Sciences, PO Box 2000, FI-33101 University of Tampere, Finland. Tel: +358 405596028, email: laura.takala@fimnet.fi

Key Words: Breast cancer, chemotherapy, antiemetics. targeted therapies. Treatment decisions are based on individual assessments $(4,5)$.

Chemotherapy is one of the most commonly used cancer treatments, and is well-known for its adverse effects. Common adverse events that lead to hospitalization are fatigue, fever, infection, low blood counts, dehydration, electrolyte disorders, nausea, diarrhoea, anaemia and deep venous thrombosis or pulmonary embolism (6).

The cyclophosphamide-epirubicin-5-fluorouracil (CEF) combination is a standard regimen used for patients with breast cancer with moderate and high recurrence risk. CEF is a highly emetogenic chemotherapy (HEC) $(5,7)$. Although many antiemetic agents have been developed during the past 20 years, chemotherapy-induced nausea and vomiting (CINV) are still two of the most problematic side-effects of chemotherapeutic agents $(8,9)$. Previous studies have shown that CINV affects quality of life and increases treatment costs; therefore, CINV requires the best possible treatment $(6,9)$.

International antiemetic guidelines recommend the use of corticosteroids, 5-hydroxytryptamine 3-(5-HT3) receptor antagonists and neurokinin 1 (NK1) receptor antagonists with $\operatorname{HEC}(7,10)$. Aprepitant (NK1 receptor antagonist) is one of the latest additions to the available antiemetic agents. Aprepitant inhibits the binding of substance P to NK1 receptors in the central nervous system and seems to be effective for both acute and delayed nausea $(11,12)$. Several studies showed the benefits of using aprepitant with HEC in patients with different tumour types (12-16).

Although research has been carried out on aprepitant, only a few studies have been conducted with patients receiving CEF as their breast cancer treatment $(14,17)$. However, the clinical benefits of aprepitant have been evident in patients with breast cancer receiving HEC in the clinical setting at Tampere University Hospital in Tampere, Finland. CEF chemotherapy is highly emetogenic, and to our knowledge, there have been no studies regarding antiemetic prophylaxis for CINV when CEF is used as an adjuvant treatment.

The aim of this study was to compare the antiemetic efficacy of the combination of aprepitant in therapy with dexamethasone, 5-HT3 receptor antagonists with the same 
therapy without aprepitant in patients receiving CEF as an adjuvant treatment for breast cancer. These non-selective patients were chosen from the usual treatment population and thus provide information about preventing emesis in the common clinical context.

\section{Materials and Methods}

The study was a retrospective analysis of 229 consecutive breast cancer patients treated with the CEF regimen between 2004 and 2014 at the Department of Oncology at the Tampere University Hospital. All the patients had moderate or high risk of breast cancer recurrence. CEF was composed of $600 \mathrm{mg} / \mathrm{m}^{2}$ cyclophosphamide, $75 \mathrm{mg} / \mathrm{m}^{2}$ epirubicin and $600 \mathrm{mg} / \mathrm{m}^{2}$ 5-fluorouracil administered i.v. on day 1 , every 3 weeks. All the patients received three cycles of treatment CINV events were classified using the Common Terminology Criteria for Adverse Events v4.0 (CTAE v4.0) (18) and were collected from the patient records, in which the patients had evaluated the nausea grade in collaboration with their treating physician.

Patients were divided into two cohorts according to the antiemetic treatment they received. In cohort 1 , the patients received $1 \mathrm{mg}$ or 2 $\mathrm{mg}$ granisetron on day 1 and $8 \mathrm{mg}$ dexamethasone on days 1 and 2 . Some patients received dexamethasone on days 3 to 8 in cohort 1 . In cohort 2, the patients received a single dose of granisetron $(1 \mathrm{mg}$ or $2 \mathrm{mg}$ ) on day $1,8 \mathrm{mg}$ dexamethasone on days 1,2 and 3, and 125 $\mathrm{mg}$ aprepitant orally on day 1 and $80 \mathrm{mg}$ on days 2 and 3 .

In both cohorts, the first-line 5-HT3-antagonist was granisetron. If CINV was uncontrolled, it was possible to change the 5-HT3antagonist to ondansetron or palonosetron. Patients were also able to receive lorazepam as part of the antiemetic combination.

The baseline data of these cohorts are shown in Table I. Cohort 1 had 132 patients, and cohort 2 had 97 patients. The median age was 53 years in cohort 1 and 56 years in cohort 2 . The primary tumour size was mostly $\mathrm{T} 1$ in both cohorts. Hormonal receptor, HER2 and menopausal status differed slightly between the groups. However, anti-HER2-targeted and hormonal treatments were not used during the CEF cycles in either group. Therefore, the variation of these factors between the cohorts was not considered relevant in this study of emesis-preventing agents during CEF therapy.

Permission to perform this retrospective evaluation was obtained from the local Ethical Committee (R15115) without informed consent from the patients.

Statistical significance was set at $p<0.05$. The statistical analysis (chi-squared test) was performed with SPSS Statistics for Windows (version 21.0) (IBM, Armonk, NY, USA). The primary outcome was to compare the grades of emesis between cohorts 1 and 2 . The study was approved by the local Ethical Committee.

\section{Results}

During three CEF cycles, less than one-third (27.5\%) of all the patients were free from nausea. Half of the patients $(50.2 \%)$ had mild emesis, and a fifth of the patients $(21.0 \%)$ had moderate emesis. Life-threatening nausea and vomiting was not observed in either cohort. The frequency of nausea in cohort 1 and cohort 2 is shown in Table II.

The patients in cohort 2 had significantly lower rates of emesis and vomiting during the overall course of all cycles
Table I. Patient characteristics.

\begin{tabular}{|c|c|c|}
\hline & Cohort 1 & Cohort 2 \\
\hline No. of patients & 132 & 97 \\
\hline \multicolumn{3}{|l|}{ Age, years } \\
\hline Median (range) & $53(29-79)$ & $56(32-82)$ \\
\hline \multicolumn{3}{|c|}{ Menopause status, $\mathrm{n}$} \\
\hline Premenopausal & 49 & 23 \\
\hline Postmenopausal & 79 & 64 \\
\hline Missing & 4 & 10 \\
\hline \multicolumn{3}{|c|}{ Primary tumor size, $n$} \\
\hline $\mathrm{T} 1$ & 60 & 53 \\
\hline $\mathrm{T} 2$ & 25 & 42 \\
\hline $\mathrm{T} 3$ & 6 & 2 \\
\hline $\mathrm{T} 4$ & 5 & 0 \\
\hline \multicolumn{3}{|c|}{ Regional lymph node status, $\mathrm{n}$} \\
\hline No & 29 & 59 \\
\hline N1 & 70 & 25 \\
\hline $\mathrm{N} 2$ & 24 & 12 \\
\hline $\mathrm{N} 3$ & 9 & 1 \\
\hline \multicolumn{3}{|l|}{ Tumor grade, $n$} \\
\hline 1 & 11 & 2 \\
\hline 2 & 54 & 33 \\
\hline 3 & 67 & 62 \\
\hline \multicolumn{3}{|l|}{ Hormonal status, $\mathrm{n}$} \\
\hline Positive & 98 & 53 \\
\hline Negative & 34 & 44 \\
\hline \multicolumn{3}{|c|}{ HER2 receptor status, $n$} \\
\hline Positive & 56 & 97 \\
\hline Negative & 76 & 0 \\
\hline
\end{tabular}

HER2: Human epidermal growth factor receptor 2.

$(p<0.05)$. In cohort 1 and cohort $2,73.1 \%$ and $85.6 \%$ of patients, respectively, had no emesis or only mild emesis. In cohort 1 and cohort 2, approximately one-quarter (26.9\%) and a little over one-tenth (14.4\%) of the patients, respectively, suffered from moderate or severe nausea.

Complete response rates (no nausea, i.e. nausea grade 0) were also significantly lower in cohort 1 than in cohort 2 $(p<0.05)$. Approximately $40.2 \%$ of patients in cohort 2 and $18.5 \%$ patients in cohort 1 had a complete response to antiemetic treatment.

In cohort 2, 86.6\% experienced no vomiting, and more than $95 \%$ of the patients had either no vomiting or only mild vomiting (Table III). A slightly lower proportion of patients in cohort 1 experienced no vomiting, but the frequency of moderate or severe vomiting was significantly higher in cohort 1 than in cohort 2.

According to the analysis of background factors, postmenopausal patients and patients over 50 years of age experienced less emesis than premenopausal patients $(p<0.05)$ and patients under 50 years of age $(p<0.05)$. Otherwise, no significant risk factors for CINV and vomiting were detected. 
Table II. Frequency of nausea in cohorts 1 and 2.

\begin{tabular}{lccccc}
\hline & \multicolumn{3}{c}{ Severity of nausea, $\mathrm{n}(\%)$} \\
\cline { 2 - 6 } Cohort & None & Mild & Moderate & Severe & Not known \\
\hline 1 & $24(18.2 \%)$ & $71(53.8 \%)$ & $34(25.8 \%)$ & $1(0.8 \%)$ & 0 \\
2 & $39(40.2 \%)$ & $44(45.4 \%)$ & $14(14.4 \%)$ & 0 & 0 \\
\hline
\end{tabular}

Table III. Frequency of vomiting in cohorts 1 and 2.

\begin{tabular}{lccccc}
\hline & \multicolumn{4}{c}{ Severity of nausea, $\mathrm{n}(\%)$} \\
\cline { 2 - 5 } Cohort & None & Mild & Moderate & Severe & Not known \\
\hline 1 & $97(73.5 \%)$ & $12(9.1 \%)$ & $19(14.4 \%)$ & $2(1.5 \%)$ & $2(1.5 \%)$ \\
2 & $84(86.6 \%)$ & $9(9.3 \%)$ & $4(4.1 \%)$ & 0 & 0 \\
\hline
\end{tabular}

\section{Discussion}

The results of this study show that aprepitant clearly reduces the amount of moderate and severe nausea experienced while undergoing a HEC when compared to an antiemetic regimen without aprepitant. These results are in agreement with the international guidelines of the European Society of Medical Oncology (5), the American Society of Clinical Oncology (10) and the Multinational Association of Supportive Care in Cancer (7). These guidelines recommend the use of NK1 receptor antagonists, 5-HT3 receptor antagonists and dexamethasone during HEC therapy.

In previous studies, the antiemetic combination of NK1 receptor antagonists, 5-HT3 receptor antagonists and dexamethasone was found to achieve a complete response (no emesis or rescue) in approximately $70 \%$ of patients (7, 10,13 ). The complete response (no nausea in all three cycles) rate in this study was approximately $40 \%$ in the patients receiving aprepitant. When complete response rate was set as nausea grade 1 or less (no nausea or mild nausea), it was achieved in approximately $85 \%$ of patients in all three cycles.

In our study, granisetron was used by $95.2 \%$ of the patients. Only $4.4 \%$ used palonosetron, and $0.4 \%$ used ondansetron. Therefore, statistical analyses comparing the 5-HT3 receptor antagonists could not be performed. However, the results of this study show that aprepitant was effective when combined with granisetron. Previous studies on the use of NK1 receptor antagonists compared with older antiemetic medications were usually conducted with ondansetron or palonosetron. Additionally, most of these studies were conducted with cisplatin-based chemotherapy $(13,15,16,19-21)$.
Internationally, there has been debate about whether palonosetron is more efficient than other 5-HT3 receptor antagonists when it is combined with an NK1 receptor antagonist $(7,13,22)$. It seems that palonosetron is not more effective when combined with aprepitant than any other 5HT3 receptor antagonist (7), although though some studies have suggested otherwise [reviewed in (22)].

Recently, a meta-analysis showed that olanzapine was an effective antiemetic in the preventive and breakthrough settings (23). In the American Society of Clinical Oncology guidelines, a combination of netupitant (NK1 receptor antagonist) and palonosetron is recommended as an effective antiemetic treatment $(10,20)$. Lorazepam was added to the antiemetic regimens for some of the patients in this study, but it was taken only if necessary, and therefore, statistical analysis on the use of lorazepam could not be performed.

The patients in this study were representative of patients with breast cancer in general and comprised mostly patients with an aggressive cancer type (see Table I). The aim was to study the effectiveness of antiemetic medications when a HEC was used, and therefore, HER2-positive patients were over-represented in the sample. Although the patients in the study were not randomized, they also were not selected based on any criteria and represented general practice patients well.

The known risk factors for more severe nausea grade are female gender, a younger age during chemotherapy cycles, platinum-or anthracycline-based chemotherapy, low alcohol consumption and a previous history of morning sickness. Additionally, the degree of nausea is usually higher during the earlier cycles of chemotherapy, and nausea during earlier cycles predicts more severe nausea in later cycles $(24,25)$. 
Our findings regarding nausea risk factors are in line with this prior knowledge. Additionally, the participants in this study were all women and therefore were at greater risk for nausea of grade 2 or greater.

Although the retrospective setting somewhat limits our study, and there was no randomization, the patients who received aprepitant were not selected based on any criteria. The treatment did not differ from the usual treatment protocol followed in our clinic, and the nausea grade was assessed by the physicians and the patients.

In the future, more research on different antiemetic combinations is needed. We need further study on different 5-HT3 receptor antagonists combined with aprepitant. In addition, olanzapine is an interesting antiemetic when administered as a single anti-emetic or in combination with 5HT3 receptor antagonists, dexamethasone and aprepitant (26).

In conclusion, CINV and vomiting can be successfully prevented with an antiemetic treatment, and effective antiemetic treatment is important for patients undergoing adjuvant anthracycline-based chemotherapy for breast cancer.

\section{References}

1 WHO I Breast cancer: prevention and control. Available at: http://www.who.int/cancer/detection/breastcancer/en/

2 Global Cancer Observatory. Available at: http://gco.iarc.fr/

3 Finnish Cancer Registry. Cancer statistics. Available at: http://www.cancer.fi/syoparekisteri/en/statistics/cancer-statistics/.

4 Senkus E, Kyriakides S, Ohno S, Penault-Llorca F, Poortmans P, Rutgers E, Zackrisson S, Cardoso F and ESMO Guidelines Committee: Primary breast cancer: ESMO Clinical Practice Guidelines for diagnosis, treatment and follow-up. Ann Oncol 26: 8-30, 2015.

5 Cardoso F, Costa A, Senkus E, Aapro M, André F, Barrios CH, Bergh J, Bhattacharyya G, Biganzoli L, Cardoso MJ, Carey L, Corneliussen-James D, Curigliano G, Dieras V, El Saghir N, Eniu A, Fallowfield L, Fenech D, Francis P, Gelmon K, Gennari A, Harbeck N, Hudis C, Kaufman B, Krop I, Mayer M, Meijer H, Mertz S, Ohno S, Pagani O, Papadopoulos E, Peccatori F, Penault-Llorca F, Piccart MJ, Pierga JY, Rugo H, Shockney L, Sledge G, Swain S, Thomssen C, Tutt A, Vorobiof D, Xu B, Norton L and Winer E: 3rd ESO-ESMO International Consensus Guidelines for Advanced Breast Cancer (ABC 3). Ann Oncol 28: 16-33, 2017.

6 Hassett MJ, O'Malley AJ, Pakes JR, Newhouse JP and Earle CC: Frequency and cost of chemotherapy-related serious adverse effects in a population sample of women with breast cancer. J Natl Cancer Inst 98: 1108-1117, 2006.

7 Roila F, Herrstedt J, Aapro M, Gralla RJ, Einhorn LH, Ballatori E, Bria E, Clark-Snow RA, Espersen BT, Feyer P, Grunberg SM, Hesketh PJ, Jordan K, Kris MG, Maranzano E, Molassiotis A, Morrow G, Olver I, Rapoport BL, Rittenberg C, Saito M, Tonato M, Warr D and ESMO/MASCC Guidelines Working Group: Guideline update for MASCC and ESMO in the prevention of chemotherapy-and radiotherapy-induced nausea and vomiting: results of the Perugia consensus conference. Ann Oncol 21(Suppl 5): 232, 2010.
8 Bloechl-Daum B, Deuson RR, Mavros P, Hansen M and Herrstedt J: Delayed nausea and vomiting continue to reduce patients' quality of life after highly and moderately emetogenic chemotherapy despite antiemetic treatment. J Clin Oncol 24: 4472-4478, 2006.

9 Farrell C, Brearley SG, Pilling M and Molassiotis A: The impact of chemotherapy-related nausea on patients' nutritional status, psychological distress and quality of life. Support Care Cancer 21: 59-66, 2013.

10 Hesketh PJ, Bohlke K, Lyman GH, Basch E, Chesney M, ClarkSnow RA, Danso MA, Jordan K, Somerfield MR, Kris MG and American Society of Clinical Oncology: Antiemetics: American Society of Clinical Oncology Focused Guideline Update. J Clin Oncol 34: 381-386, 2016.

11 Diemunsch P and Grelot L: Potential of substance P antagonists as antiemetics. Drugs 60: 533-546, 2000.

12 Hesketh PJ: Chemotherapy-induced nausea and vomiting. N Engl J Med 358: 2482-2494, 2008.

13 Kitamura H, Takahashi A, Hotta H, Kato R, Kunishima Y, Takei F, Horita H, Masumori $\mathrm{N}$ and Sapporo Medical University Urologic Oncology Consortium: Palonosetron with aprepitant plus dexamethasone to prevent chemotherapy-induced nausea and vomiting during gemcitabine/cisplatin in urothelial cancer patients. Int J UroI 22: 911-914, 2015.

14 Roila F, Ruggeri B, Ballatori E, Del Favero A and Tonato M: Aprepitant versus dexamethasone for preventing chemotherapyinduced delayed emesis in patients with breast cancer: a randomized double-blind study. J Clin Oncol 32: 101-106, 2014.

15 Silvestris N, Brunetti AE, Russano M and Nardulli P: Optimal control of nausea and vomiting with a three-drug antiemetic regimen with aprepitant in metastatic pancreatic cancer patients treated with first-line modified FOLFIRINOX. Support Care Cancer 21: 2955-2956, 2013.

16 Hesketh PJ, Grunberg SM, Gralla RJ, Warr DG, Roila F, de Wit R, Chawla SP, Carides AD, Ianus J, Elmer ME, Evans JK, Beck K, Reines S, Horgan KJ and Aprepitant Protocol 052 Study Group: The oral neurokinin-1 antagonist aprepitant for the prevention of chemotherapy-induced nausea and vomiting: a multinational, randomized, double-blind, placebo-controlled trial in patients receiving high-dose cisplatin - the Aprepitant Protocol 052 Study Group. J Clin Oncol 21: 4112-4119, 2003.

17 Nakayama Y, Ito Y, Tanabe M, Takahashi S and Hatake K: A combination of aprepitant, palonosetron, and dexamethasone prevents emesis associated with anthracycline-containing regimens for patients with breast cancer. A retrospective study. Breast Cancer 22: 177-184, 2015.

18 Common Terminology Criteria for Adverse Events (CTCAE v4.0). Available at: https://ctep.cancer.gov/protocoldevelopment/ electronic_applications/ctc.htm\#ctc_40.

19 Longo F, Mansueto G, Lapadula V, De Sanctis R, Quadrini S, Grande R, Gori B, Altavilla A, D’Antoni I, Del Signore E, Stumbo L, De Luca C, Cimadon B, Cortesi E, Gamucci T and Di Seri M: Palonosetron plus 3-day aprepitant and dexamethasone to prevent nausea and vomiting in patients receiving highly emetogenic chemotherapy. Support Care Cancer 19: 1159-1164, 2011.

20 Lorusso V, Karthaus M and Aapro M: Review of oral fixed-dose combination netupitant and palonosetron (NEPA) for the treatment of chemotherapy-induced nausea and vomiting. Future Oncol 11: 565-577, 2015. 
21 Zhang Y, Yang Y, Zhang Z, Fang W, Kang S, Luo Y, Sheng J, Zhan J, Hong S, Huang Y, Zhou N, Zhao $\mathrm{H}$ and Zhang L: Neurokinin-1 receptor antagonist-based triple regimens in preventing chemotherapy-induced nausea and vomiting: A network meta-analysis. J Natl Cancer Inst 109: 1-11, 2017.

22 Saito M, Aogi K, Sekine I, Yoshizawa H, Yanagita Y, Sakai H, Inoue K, Kitagawa C, Ogura T and Mitsuhashi S: Palonosetron plus dexamethasone versus granisetron plus dexamethasone for prevention of nausea and vomiting during chemotherapy: a double-blind, double-dummy, randomised, comparative phase III trial. Lancet Oncol 10: 115-124.

23 Chiu L, Chow R, Popovic M, Navari RM, Shumway NM, Chiu N, Lam H, Milakovic M, Pasetka M, Vuong S, Chow E and DeAngelis C: Efficacy of olanzapine for the prophylaxis and rescue of chemotherapy-induced nausea and vomiting (CINV): A systematic review and meta-analysis. Support Care Cancer 24: 2381-2392, 2016.

24 Bouganim N, Dranitsaris G, Hopkins S, Vandermeer L, Godbout L, Dent S, Wheatley-Price P, Milano C and Clemons M: Prospective validation of risk prediction indexes for acute and delayed chemotherapy-induced nausea and vomiting. Curr Oncol 19(6): e414-e421, 2012.
25 Dranitsaris G, Molassiotis A, Clemons M, Roeland E, Schwartzberg L, Dielenseger P, Jordan K, Young A and Aapro M: The development of a prediction tool to identify cancer patients at high risk for chemotherapy-induced nausea and vomiting. Ann Oncol 28: 1260-1267, 2017.

26 Sato J, Kashiwaba M, Komatsu H, Ishida K, Nihei S and Kudo $\mathrm{K}$ : Effect of olanzapine for breast cancer patients resistant to triplet antiemetic therapy with nausea due to anthracyclinecontaining adjuvant chemotherapy. Jpn J Clin Oncol 46: 415$420,2016$.
Received November 5, 2018

Revised November 28, 2018

Accepted November 29, 2018 